\title{
Effectiveness of Low Vision Aids in patients with low vision attending a medical college hospital
}

\author{
Abdul Aziz A. ${ }^{1}$, Kulkarni U. ${ }^{2 *}$ \\ DOI: https://doi.org/10.17511/jooo.2020.i04.02 \\ ${ }^{1}$ Almas Abdul Aziz, Assistant Professor, College of Optometry, Al Salama Eye Hospital, Malappuram, Kerala, India. \\ 2* Uma Kulkarni, Professor, Department of Ophthalmology, Yenepoya Medical College, Mangalore, Karnataka, India.
}

Introduction:Low vision is defined as visual impairment despite treatment, surgery, or standard refractive correction, but with the potential to use the residual vision. The aim of the study was to explore the clinical profile of patients requiring Low Vision Aids (LVA) and assess the effectiveness, of LVA among patients with low vision. Material and Methods: Fifty patients fulfilling the criteria of low vision were recruited after obtaining informed written consent and detailed ocular evaluation was done to detect the cause of low vision. A trial of LVAs was done for near using hand-held magnifiers (+6D, +14D, +20D), stand magnifiers $(+8 \mathrm{D},+14 \mathrm{D},+20 \mathrm{D})$ and spectacle magnifiers $(+6 \mathrm{D},+10 \mathrm{D},+14 \mathrm{D},+20 \mathrm{D})$ and visual improvement was noted. Similarly, LVAs were tried for distance using telescope $2.5 \mathrm{X}$ and clip-on telescope $3 \mathrm{X}$. Results: The majority of the participants $(72 \%)$ belonged to the upper lower class. The most common causes of low vision were heritable conditions like retinitis pigmentosa (24\%), bilateral primary optic atrophy (18\%), and macular dystrophies $(16 \%)$. The most effective low vision aids were handheld and stand magnifiers which improved vision by one to four lines. The magnifiers were most effective in eyes with macular dystrophy, retinitis pigmentosa, and age-related macular degeneration. Conclusion:Low vision aids are potential methods of improving the residual vision in low vision patients. In the background of the high and increasing prevalence of low vision and poor awareness about low vision aids among them, efforts are necessary to rehabilitate them with affordable and accessible low vision services.

Keywords: Low vision, Residual vision, Low Vision Aids, Handheld and stand magnifiers, Telescopes

Corresponding Author

Uma Kulkarni, Professor, Department of Ophthalmology, Yenepoya Medical College, Mangalore, Karnataka, India.

Email: umasripada@gmail.com
How to Cite this Article

To Browse

Aziz AA, Kulkarni U. Effectiveness of Low Vision Aids in patients with low vision attending a medical college hospital. Trop J Ophthalmol Otolaryngol. 2020;5(4):89-96.

Available From

https://opthalmology.medresearch.in/index.php/jooo /article/view/137

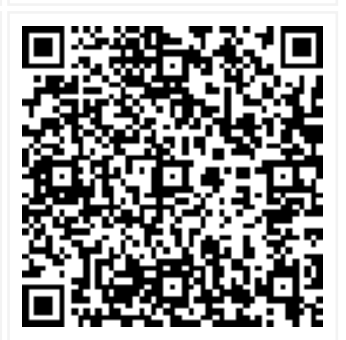

\begin{tabular}{|c|c|c|c|c|}
\hline & $\begin{array}{c}\text { Manuscript Received } \\
2019-02-20\end{array}$ & $\begin{array}{c}\text { Review Round } 1 \\
2019-03-01\end{array}$ & $\begin{array}{c}\text { Review Round } 2 \\
2019-03-06\end{array}$ & Review Round 3 \\
\hline & $\begin{array}{c}\text { Conflict of Interest } \\
\text { No }\end{array}$ & $\begin{array}{c}\text { Funding } \\
\mathrm{Nil}\end{array}$ & $\begin{array}{c}\text { Ethical Approval } \\
\text { Yes }\end{array}$ & $\begin{array}{c}\text { Plagiarism X-checker } \\
5 \%\end{array}$ \\
\hline OPEN & $\begin{array}{l}\text { (c) } 2020 \text { by } \\
\text { AcCESS }\end{array}$ & $\begin{array}{l}\text { z, Uma Kulkarni ar } \\
\text { ss article licensed } \\
\text { https://creativecc }\end{array}$ & $\begin{array}{l}\text { by Siddharth Health } \\
\text { ive Commons Attrib } \\
\text { licenses/by/4.0/ unp }\end{array}$ & $\begin{array}{l}\text { Social Welfare Society. This is an } \\
\text { national License } \\
\text { t.0]. }\end{array}$ \\
\hline
\end{tabular}




\section{Introduction}

Low vision (LV) is a form of visual impairment, which remains uncorrected with routine medical, surgical, or refractive means. Worldwide, about 110 million persons have low vision and are at great risk of becoming blind (2002) [1]. The prevalence is higher in the developing world, and among the illiterate, unemployed, and rural residents [2] LV is found to affect more than $3 \%$ of the south Indian population [3]. LV can affect personal, professional, and social life. Among older people with low vision, $30 \%$ have problems with medicine management [4]. This may affect self-care during illnesses. The common causes of LV include retinal diseases, amblyopia, optic atrophy, glaucoma, corneal diseases [5].

Low vision aids (LVAs) play a major role in LV rehabilitation. Optical LVAs maximize the utilization of residual vision fordistance using telescopes and near using magnifiers in approximately $70 \%$ and $86 \%$ of the patients, respectively [6]. LV As are available for various tasks and distances and range from simple magnifying lenses, telescopes to high power video-magnifiers. In India, only bigger eye care centers dispense LVAs, the smaller clinics do not. Also, only about half of the ophthalmologists were aware, and on-third had knowledge about low vision services in an Indian study [7].

This is compounded by the poor utilization of only 3$15 \%$ of the low vision services globally [8]. To maximize rehabilitation of individuals with $L V$, the present study explores the causes of LV among patients presenting to a medical college hospital and to assess the effectivenessof LVAs. This will help eye care centers in planning and providing an effective rehabilitative "low vision service" to avoid needless blindness.

\section{Methodology}

The present study was adescriptive studyin theOphthalmology department of a Medical College Hospital in South India over a period of 2 years after obtaining clearance from the Institutional Ethics Committee. Participants were recruited by 'convenience sampling' after administering an informed written consent. The sample size was calculated as 46 rounded off to 50, using the formula $S=Z \times p(1-p) / m 2$ considering $95 \%$ confidence interval and $5 \%$ allowable error and based on $2.9 \%$ prevalence of LVin south India [3].
The inclusion criteria were adults of either gender with LV. LV was defined as per ICD-10 Visual Impairment categories as visual acuity less than $6 / 18$, but equal to or better than the perception of light or a corresponding visual field loss to less than 10 degrees in the better eye with best possible correction.

The current study excluded those with LV with concurrent affection of higher mental functions, which made an assessment, and use of LVA difficult. Those cases of corneal opacities, dense posterior sub-capsular cataract, and diabetic maculopathy for which potential treatment/ surgical options were possible and planned were not included in the study.

Single author (AA) tested the visual acuity using the 3-meter LogMAR chart, and near vision test using standard near vision flip charts at a working distance of $25-30 \mathrm{~cm}$ in all 50 cases. A detailed ocular examination was done using slit-lamp biomicroscopy and a +78D lens. Trial of LVAs for reading was done using handheld $(+6 D,+14 D$ and $+20 \mathrm{D})$, stand-mounted ( $+8 \mathrm{D},+14 \mathrm{D}$ and $+20 \mathrm{D})$ and spectacle magnifiers (+6D, +10D, +14D, +20D). Trial of LVAs for distance was done using $2.5 \times$ and clip-on telescope. Improvement in vision was noted as the number of lines of improvement on the respective charts.

\section{Results and Analysis}

A total of 50 patients were included in the study and evaluated to find the patterns and concerns of the utilization of low vision aids among patients with low vision. None of them was already using LVA.

Socio-demographic distribution:The study group consisted of 37 males and 13 females with a Male: Female gender ratio of 2.84:1.The mean age of the study group was similar 47.9 years \pm 17.27 (Males: $47.45 \pm 17.36$ years and Females $49.15 \pm 15.09$ years) with an age range 18-72 years. The age and gender distribution of the 50 subjects are presented in Figure 1. Most of them belonged to the upper lower class by Kuppusamy'sclassification (72\%).

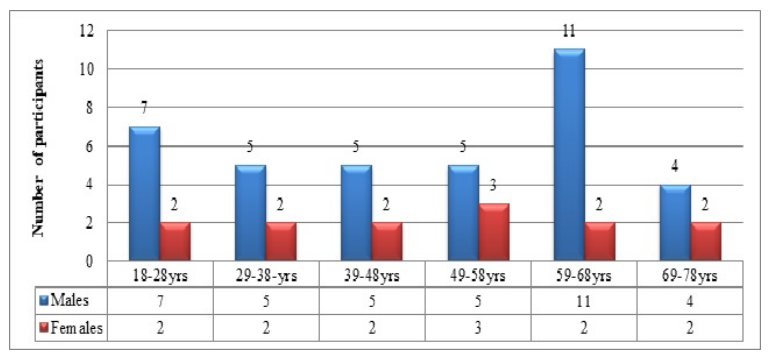




\section{Fig-1: Demographic distribution}

Visual impairment: About $46 \%$ of the participants hadBCVA in the range 1.07 to 1.77 (46\%) and44\% in the range of $0.477-1$ in the better eyes. BCVA was almost identical in both eyes in all the 50 participants. $40 \%$ had near vision worse than N36, and only $18 \%$ improved to $\mathrm{N} 6$ with routine optical correction, the rest hadnear vision between $\mathrm{N} 8$ to N36. Most had visual impairment for less than 10 years $(72 \%), 20 \%$ for $10-20$ years, and $8 \%$ for more than 20 years. Nine patients had symptoms of night blindness.66\% were hypermetropic, 20\% myopic and the rest were emmetropic.

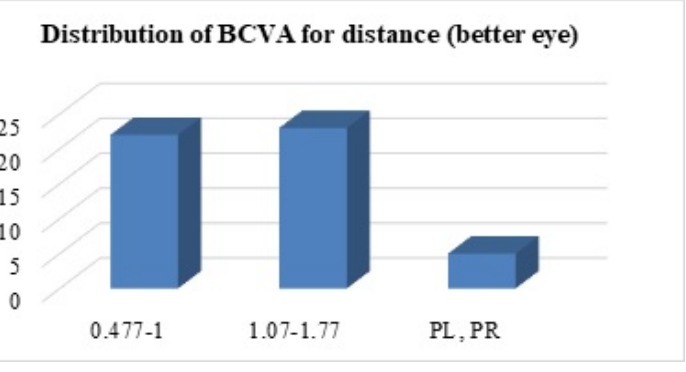

Fig-2: BCVA distance.

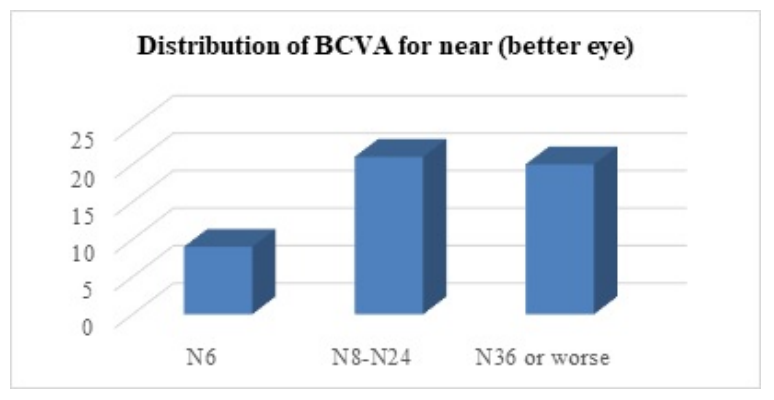

Fig-3: BCVA Near.

01. Ocular findings: Ten eyes were pseudophakic, one participant has bilateral aphakia and the rest were phakic. 12 (24\%) had bilateral sluggishly reacting pupils.

02. Causes for Iow vision: Advanced retinitis pigmentosa with consecutive optic atrophy was the most common cause for low vision (24\%). Primary optic atrophy $(18 \%)$, age-related macular degeneration (16\%), macular dystrophy (12\%), macular scar (10\%), and myopic maculopathy (8\%) were the next common causes of $\mathrm{LV}$, in that order. The least common causes included diabetic maculopathy, toxic amblyopia, cortical blindness, old retinal detachment, and unexplained loss of vision, seen in $2 \%$ each. There was one case of concurrent high myopia and retinitis pigmentosa
(2\%). The details are given in Figure 4.

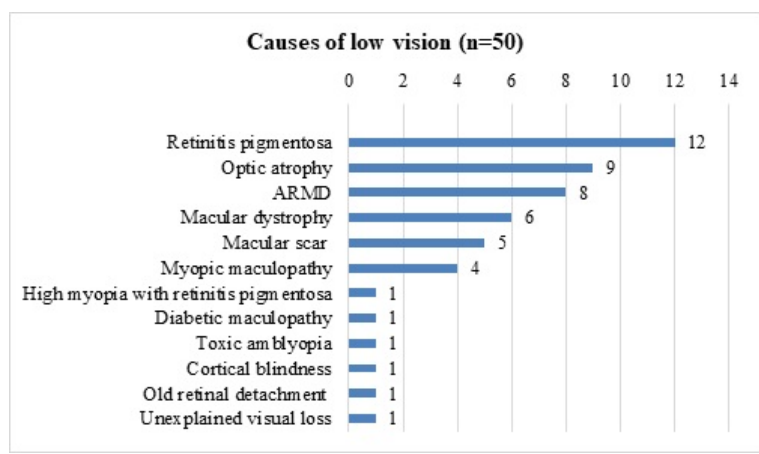

Fig-4: Causes of Low vision.

01. Effectiveness of LVAs for near: Hand and stand magnifiers showed similar improvement in vision and the improvement was better than with spectacle magnifiers.

01. Hand-held and stand magnifiers: Of the 50 participants, $15(30 \%)$ improved with both hand-held and stand magnifiers. The average number of lines improved with these magnifiers was 1.87 . Most $(9,60 \%)$ of those who improved with magnifiers showed only one-line improvement in vision; whereas 2, 3 , or 4 lines improvement was seen in 2 $(13.3 \%), 1$ (6.7\%), and 3 (20\%) respectively.

02. Spectacle magnifiers: Of the 50 participants, spectacle magnifiers improved vision in only $9(18 \%)$ of the participants. The average improvement was 1.44 lines. Most of those who improved with spectacle magnifiers showed 1-line improvement (66.70\%), whereas 2-line improvement was seen in only $2(22.2 \%)$, whereas 3 line improvement was seen in 1 (11.11\%). None of them showed 4-line improvement.All those who showed improvement with spectacle magnifiers also showed improvement with the hand-held and stand magnifiers.

Table-1: Effectiveness of LVAs for near.

\begin{tabular}{|l|l|l|l|l|}
\hline \multirow{2}{*}{$\begin{array}{c}\text { Conditions where LVAs } \\
\text { showed improvement }\end{array}$} & $\begin{array}{c}\text { Numbers } \\
\text { improved } \\
(\%)\end{array}$ & $\begin{array}{r}\text { Age/ } \\
\text { Sex }\end{array}$ & \multicolumn{2}{|c|}{$\begin{array}{r}\text { Number of lines } \\
\text { improved }\end{array}$} \\
\cline { 3 - 5 } & & $\begin{array}{l}\text { Magnifiers } \\
\text { (HH/Stand }\end{array}$ & $\begin{array}{l}\text { Magnifier } \\
\text { (Spectacle) }\end{array}$ \\
\hline Retinitis pigmentosa with & $3(25)$ & $55 / \mathrm{M}$ & 1 & 1 \\
\cline { 3 - 6 } & & $62 / \mathrm{M}$ & 1 & 1 \\
\cline { 3 - 6 } & & $59 / \mathrm{F}$ & 1 & 1 \\
\hline
\end{tabular}




\begin{tabular}{|l|l|l|l|l|}
\hline Primary optic atrophy & $1(11.11)$ & $30 / \mathrm{M}$ & 1 & 1 \\
\hline ARMD & $2(25)$ & $65 / \mathrm{M}$ & 2 & 2 \\
\cline { 3 - 5 } & & $70 / \mathrm{M}$ & 2 & 2 \\
\hline Macular dystrophy & $4(66.67)$ & $40 / \mathrm{M}$ & 4 & 0 \\
\cline { 3 - 5 } & & $22 / \mathrm{M}$ & 4 & 0 \\
\cline { 3 - 5 } & & $35 / \mathrm{M}$ & 1 & 3 \\
\cline { 3 - 5 } & & $31 / \mathrm{M}$ & 1 & 0 \\
\hline Macular scar & $1(20)$ & $68 / \mathrm{F}$ & 3 & 0 \\
\hline Diabetic maculopathy & $1(100)$ & $56 / \mathrm{F}$ & 1 & 0 \\
\hline Toxic amblyopia & $1(100)$ & $46 / \mathrm{M}$ & 1 & 1 \\
\hline Cortical blindness & $1(100)$ & $18 / \mathrm{M}$ & 1 & 0 \\
\hline Unexplained visual loss & $1(100)$ & $60 / \mathrm{M}$ & 4 & 1 \\
\hline Rest of the conditions (70\%) did not improve with LVAs & & \\
\hline
\end{tabular}

04. Effectiveness of LVAs for distance: Only seven $(14 \%)$ showed some improvement with the telescope for distance $2.5 \mathrm{X}$, while rest $(86 \%)$ had none. Only two (4\%) improved with clip-on telescope whereas the rest (96\%) had none. The details are provided in table 2 . All the LVAs for distance showed only 1-line improvement.

Table-2: Effectiveness of LVAs for distance.

\begin{tabular}{|c|c|c|c|c|}
\hline \multirow[t]{2}{*}{$\begin{array}{l}\text { Conditions where LVAs } \\
\text { showed improvement }\end{array}$} & \multirow[t]{2}{*}{$\begin{array}{c}\text { Numbers } \\
\text { improved (\%) }\end{array}$} & \multirow[t]{2}{*}{$\begin{array}{c}\text { Age/ } \\
\text { Sex }\end{array} \mid$} & \multicolumn{2}{|c|}{$\begin{array}{c}\text { Number of lines } \\
\text { improved }\end{array}$} \\
\hline & & & $\begin{array}{l}\text { Telescop } \\
\text { e } 2.5 \mathrm{X}\end{array}$ & \begin{tabular}{|l} 
Telescope \\
Clip-on
\end{tabular} \\
\hline \multirow{2}{*}{$\begin{array}{l}\text { Retinitis pigmentosa with } \\
\text { consecutive optic atrophy }\end{array}$} & \multirow[t]{2}{*}{$2(16.6)$} & $25 / \mathrm{M}$ & 1 & - \\
\hline & & $33 / \mathrm{M}$ & 1 & 1 \\
\hline Primary optic atrophy & $1(11.11)$ & $19 / \mathrm{M}$ & 1 & - \\
\hline \multirow[t]{2}{*}{ ARMD } & \multirow[t]{2}{*}{$2(25)$} & $60 / \mathrm{M}$ & 1 & - \\
\hline & & $60 / \mathrm{M}$ & 1 & - \\
\hline \multirow{2}{*}{ Macular dystrophy } & \multirow[t]{2}{*}{$2(33.3)$} & $20 / M$ & 1 & - \\
\hline & & $31 / \mathrm{F}$ & 1 & 1 \\
\hline \multirow[t]{2}{*}{ Macular scar } & \multirow[t]{2}{*}{$2(40)$} & $69 / F$ & 1 & - \\
\hline & & $68 / F$ & 1 & - \\
\hline
\end{tabular}

\section{Discussion}

The study was conducted on 50 adults with LV in order to assess the causes and effects of LVAs.

01. Sex distribution: Among the 50 study participants, $74 \%$ were males. This is comparable with other studies on a low vision where the male preponderance ranged from $65 \%$ to $96 \%$. $[5,6,9]$. The male preponderance in the present study may be due to a higher health access rate for visual problems among the males compared to females. Sociocultural factors where the bread earners are males and seek consultation for visual problems more oftenthan females.
02. Age distribution: The mean age was 47.9 years \pm 17.27 and ranged from 18-72 years. The age group affected by the low vision in the present study had a wide range similar to other studies, but the mean age was lower than these studies which are conducted in more developed European countries (76- 81.3 years) $[10,11]$. The mean age in the present study was comparable with another study (38.8 years) conducted in the neighboring Asian country [6] It is possible that these differences reflect the variations in healthcare facilities, access, and longevity of individuals in the developed and the developing countries. Since LV is seen in the younger population in the present study, this implies a negative impact on the economics of the family, more so because the males who are the bread earners are affected during their productive period of life.

03. Socio-economic status: In the APED study [12] there was an increased association of visualimpairment with decreasing socioeconomic status. In the present study too, the majority (72\%) of the participants belonged to the modified Kuppuswamy's (2013) upper-lower socio-economic class. Although the inclusion criteria in the present study were restricted to low vision after excluding treatable causes of blindness, the association of low vision with lower socio-economic status is still comparable with the APED study, [12] which included all causes of blindness. The association between low vision and lower socioeconomic status works as a double-edged sword. The lower productivity due to low vision leads to poorer financial gains. Accordingto a study in this geographical area two-thirds of the patients with blindness were diagnosed to have depression and three-fourths of them perceived a negative impact of blindness on their occupation [13]. The resulting lower socioeconomic status leads to poor health care access and poor rehabilitation measures.

04. Vision testing: $10 \%$ of the participants had a vision as poor as the perception of light bilaterally and such patients were unsuitable for the trial of LVAs. The testing of contrast sensitivity, Amsler's grid, and color vision were extremely difficult in most of the cases.More than half of the patients could not perceive the contrast sensitivity chart as they had vision worse than 0.60 LogMAR. Color vision was normal in $70 \%$ patients probably because the method used for testing color vision was by 
Ishihara's chart which can detect only congenital color blindness. More than half of the patients had gross abnormalities in the central vision. Hence the only indicator for assessment of low vision was the distant and near vision testing. The additional tests on vision neither helped in the diagnosis of low vision nor in the prescription of LVAs

05. Causes of low vision:In the present study, the most frequent cause for low vision was retinitis pigmentosa, followed by primary optic atrophy, macular dystrophy, macular scar, and agerelated macular degeneration. The spectrum of causes of low vision in the present study was similar to other studies. In a study conducted by L.V Prasad institute, the four major causes of low vision were retinitis pigmentosa (19\%), macular diseases including heredomacular and age-related macular degeneration (17.7\%), diabetic retinopathy (13\%) and degenerative myopia (9\%) [9]. In thestudy by Li et al, the main causes of visual impairment were agerelated macular degeneration (14.3\%), degenerative myopia $(11.8 \%)$, retinitis pigmentosa $(8.9 \%)$ and diabetic retinopathy $(6.4 \%)$ [6]. In the study by Carvalho et al, [14]the major cause of vision loss among elderly patients seeking treatment at the low vision service was age-related macular degeneration $(44.0 \%)$. In the present study, the proportion of cases with retinitis pigmentosa, bilateral optic atrophy with onset in childhood (Presumed to be hereditary), and macular dystrophies was high and together accounted to $46 \%$ of the cases with low vision. This may be due to reasons similar to the study from L.V Prasad which concluded that the proportion of cases with retinitis pigmentosa leading to moderate visual loss was high due to a higher incidence of parental consanguinity in this population [9]. In a previous study in this geographic area, it has been found that the prevalence of consanguineous marriages was as high as $23.7 \%$, [15] which may explain the higher incidence of hereditary causes leading to low vision in this area. The proportion of cases with age-related macular degeneration in the present study was $16 \%$ and is comparable to other studies which could probably be attributable to the increasing life expectancy [9]. The present study excluded cases of diabetic retinopathy who were undergoing treatment for maculopathy and in whom visual
Improvement was expected. Hence the proportion of diabetic retinopathy causing low vision was low in the present study in contrast to most studies $(6.4-13 \%)[6,9]$.

06. Low vision aids: Need for LVAs: In the present study, only 50 cases with the low vision presented to our hospital in a span of 24 months. Although all of them required some measures to improve vision, LVAs improved vision only in 22 patients (44\%). 10\% of the patients had the only perception of light and hence were totally unsuitable for the prescription of LVAs. Although the incidence of low vision is as high, the number of patients presenting to the hospital is very low. This could be due to high illiteracy rates, low socioeconomic status among the population, or because of the eye condition being painless. About $95 \%$ of those with serious sight loss have some useful vision and with appropriate low vision, support can be helped to use their remaining vision. There is strong evidence that the provision of low vision services can make a positive difference inthe lives of visually impaired people[16]. In a study by Pollard,[17] many people did not identify themselves as having low vision, did not really understand the term low vision and did not understand what low vision rehabilitation might provide. Similarly, in our population also the patients presenting to the hospital for rehabilitation are very low mainly because the rehabilitation services are not well established in this area and the available services are not well promoted. The stigma and limitations associated with blindness may result in social neglect of the blind.In the present study, none of them was already using LVA. This reflects the poor utilization of LVA services [8].

- Effectiveness of LVAs for near: Only $30 \%$ of the participants showed improvement with LVAs for near vision, whereas only $14 \%$ showed improvement with LVAs for distance. In a study by Li[6] 33 succeeded in reading with optical magnifiers, and upto $69.4 \%$ benefited from the use of telescopes for distance. Similarly, $88 \%$ of patients were able to read smaller text with magnifiers in the study by Margarin [10]. 
The higher rates of benefits in this study could be due to the use of illuminated magnifiers, whereas the present study did not use illuminated LVAs. This implies that almost one-third of the patients with low vision can be rehabilitated and the visual compromise can be reversed to a useful extent, in order to improve their productivity and in turn, their quality of life.

- The types of LVA for near: The low vision aids which were found to be most beneficial to the participants with Low vision were with hand magnifiers and stand magnifiers, followed by spectacle magnifiers. In the study by Margarin[10] handheld and stand magnifiers were prescribed with similar results. While in the $\mathrm{Li}$ study, both spectacle and handheld magnifiers showed similar results, the study by Margarin[10] found that illuminated stand and handheld magnifiers had more acceptance than the non-illuminated LVAs. In the present study, the results are comparable except that illuminated LVAs were not tried on our participants. However, in the L.V Prasad study, [9] spectacle magnifiers were found to be more beneficial than stand and handheld magnifiers the reason for which has not been discussed by the authors. The better acceptance of the hand-held and stand magnifiers, when compared to the spectacle magnifiers, may be mainly due to the close working distance inherent to all magnifiers. The spectacle magnifiers being binocular require a greater effort of convergence when compared to the uniocular handheld and stand magnifiers. The advantage of the binocularity of spectacle magnifiers could not be utilized in such cases due to the additional effort of convergence and associated discomfort.There was no difference in the acceptance of the various powers of magnifiers. (6D, 14D, and 20D hand magnifiers, $8 \mathrm{D}, 14 \mathrm{D}$ and 20 stand magnifiers and 6D, 10D, 14D,
And 20D spectacle magnifiers)

- Effectiveness of LVAs for distance: The LVAs tried for distance in the present study were telescope (2.5X) and clip-on telescopes. Telescopes were found to be more beneficial than the clip-on telescopes (3X). The results of the study by Li[6]was similar to the present study in which patients who improved for distance were with telescopes $(27 \%)$ again in the L.V Prasad study[9] they used handheld distance telescopes which were useful for patients for distance activity. Most of the patients with low vision find it difficult even to do their daily routine activity. They become completely dependent on their caretakers for all activities including mobility within or beyond the house, in turn affecting their selfconfidence and mental state of mind.

07. Conditions improving with low vision aids:In the present study, a condition which benefited most with LVAs for near was macular dystrophy $(66 \%)$ followed by retinitis pigmentosa $(25 \%)$ and age-related macular degeneration $(25 \%)$. And the maximum number of lines improved for near was 4 lines. Most of the patients who improved with telescopes for distance also were those with macular dystrophy (33\%), followed by macular scar $(40 \%)$ and retinitis pigmentosa (16.7\%). All of the patients improved only 1 line with the telescope. Other studies have not compared which disorder benefitted maximum with low vision aids. Most of the patients in the L.V Prasad study[18] had improvement of 4 and more lines using magnifiers for near. While for the distance the average improvement in their study was more than 1 line. In many of the other studies, they used closed circuit CCTV as a low vision aid which was not used in the present study.

\section{Conclusion}

Low vision is a problem of significant dimension among ophthalmic patients, with predominant affection of males and individuals in the fifth decade of life.The proportion was higher in the lower socioeconomic class. 
The proportion of heritable conditions like retinitis pigmentosa, macular dystrophy, and hereditary optic atrophy as a cause of low vision in this area was high and could be due to increased consanguinity.

Almost $30 \%$ of those with low vision showed improvement in vision with LVAs. Macular dystrophies showed the best improvement with LVAs compared to other causes of low vision. Stand and hand-held magnifiers showed maximum improvement in patients with low vision with upto 4 lines of improvement in vision. Most of the conditions were so advanced that the LVAs were not effective.

Use of LVAs would positively impact the day to day activities like reading, stitching, beedi rolling, mobility, and driving, thereby improving the overall quality of life. However, there is a need to increase the visibility of low vision centers and intensifying their activities to make the LVAs accessible and affordable to all patients with low vision.

\section{What does the study add to the existing knowledge?}

The most appropriate platform for implementing this change would be strengthening the National Program for Control of Blindness to cater to the needs of the low vision patients. The duty of rehabilitating patients with residual vision by prescribing suitable and affordable LVAs should also be taken up by every practicing ophthalmologist with contributions from governmental and nongovernmental organizations. Efforts should be made to increase the visibility and impact of low vision centers. To conclude, every treating ophthalmologist should regard the low vision patient as a 'person' and not merely as 'two eyes'.

\section{Author's contribution}

Dr. Almas Abdul Aziz: Study design, concept

Dr. Uma Kulkarni: Manuscript preparation

\section{Reference}

01. Congdon NG, Friedman DS, Lietman T. Important causes of visual impairment in the world today. JAMA. 2003;290(15)2057-2060. doi: jama.290.15.2057 [Article][Crossref][PubMed] [Google Scholar]
02. Ramke J, Palagyi A, Naduvilath T, du Toit R, Brian G. Prevalence and causes of blindness and low vision in Timor-Leste. $\mathrm{Br} \mathrm{J} \mathrm{Ophthalmol.}$ 2007;91(9)1117-1121. doi: [Article][Crossref] [PubMed][Google Scholar]

03. Vijaya L, George R, Asokan R, Velumuri L, Ramesh SV. Prevalence and causes of low vision and blindness in an urban population- The Chennai Glaucoma Study. Indian J Ophthalmol. 2014;62(4)477-481. doi: org/10.4103/03014738.111186 [Article][Crossref][PubMed][Google Scholar]

04. McCann RM, Jackson AJ, Stevenson $M$, Dempster M, McElnay JC, Cupples ME. Help needed in medication self-management for people with visual impairment: case-control study. $\mathrm{Br}$ J Gen Pract. 2012;62(601):e530-e537. doi: [Article] [Crossref][PubMed][Google Scholar]

05. Dandona R, Dandona L, Srinivas M, Giridhar $P$, Nutheti R, Rao GN. Planning low vision services in India- a population-based perspective. Ophthalmol. 2002;109(10)1871-1878. doi: s01616420(02)01183-1 [Article][Crossref][PubMed] [Google Scholar]

06. Li CY, Lin KK, Lin YC, Lee JS. Low vision and methods of rehabilitation- a comparison between the past and present. Chang Gung Med J. 2002;25(3)153-161. [Crossref][PubMed][Google Scholar]

07. Jose J, Thomas J, Bhakat P, Krithica S. Awareness, knowledge, and barriers to low vision services among eye care practitioners. Oman J Ophthalmol. 2016;9(1)37-43. doi: [Article] [Crossref][PubMed][Google Scholar]

08. Sarika G, Venugopal D, Sailaja MVS, Evangeline S, Krishna Kumar R. Barriers and enablers to low vision care services in a tertiary eye care hospital- A mixed method study. Indian J Ophthalmol. 2019;67(4)536-540. doi: [Article][Crossref] [PubMed][Google Scholar]

09. Khan SA. A retrospective study of low-vision cases in an Indian tertiary eye-care hospital. Indian J Ophthalmol. 2000;48(3)201-207. [Crossref] [PubMed][Google Scholar]

10. Margrain TH. Helping blind and partially sighted people to read- the effectiveness of low vision aids. $\mathrm{Br}$ J Ophthalmol. 2000;84(8)919-921. doi: 1136/bjo.84.8.919 [Article][Crossref][PubMed] [Google Scholar] 
11. Williams GP, Pathak-Ray V, Austin MW, Lloyd AP, Millington IM, Bennett A. Quality of life and visual rehabilitation- an observational study of low vision in three general practices in West Glamorgan. Eye. 2007 Apr;21(4):575. doi: sj.eye.6702256 [Article] [Crossref][PubMed][Google Scholar]

12. Dandona $L$, Dandona $R$, Srinivas $M$, Giridhar $P$, Vilas $K$, Prasad $M N$, et al. Blindness in the Indian state of Andhra Pradesh. Invest Ophthalmol Vis Sci. 2001;42 (5)908-916. [Crossref][PubMed][Google Scholar]

13. Shetty R, Kulkarni UD. Change-readiness of the blind- a hospital based study in a coastal town of South India. Middle East Afr J Ophthalmol. 2014;21 (2)158-164. doi: [Article][Crossref][PubMed] [Google Scholar]

14. Carvalho KM, Monteiro GB, Isaac CR, Shiroma LO, Amaral MS. Causes of low vision and use of optical aids in the elderly. Rev Hosp Clin Fac Med Sao Paulo. 2004;59(4)157-160. doi: [Article] [Crossref][PubMed][Google Scholar]
15. Kulkarni $U$, Jain $R$, Savur S, Prabhu V, PD Sowmya, Rasheed $R$, et al. Perceptions and practices of consanguineous marriage and its implication in the transmission of genetic disorders among the population of South India. JAdv Res Biol Sci. 2010(2)14-18. [Crossref][PubMed][Google Scholar]

16. Leat SJ, Fryer A, Rumney NJ. Outcome of low vision aid provision- the effectiveness of a low vision clinic. Optom Vis Sci. 1994;71(3)199-206. doi: [Article][Crossref][PubMed][Google Scholar]

17. Pollard TL, Simpson JA, Lamoureux EL, Keeffe JE. Barriers to accessing low vision services. Ophthalmic Physiol Opt. 2003;23(4)321-327. doi: 1046/j.1475-1313.2003.00123.x [Article][Crossref] [PubMed][Google Scholar]

18. Dandona $R$, Dandona $L$, Srinivas $M$, Giridhar $P$, Prasad MN, Vilas $K$, et al. Moderate visual impairment in India- the Andhra Pradesh Eye Disease Study. Br J Ophthalmol. 2002;86(4)373377. doi: 10.1136/bjo.86.4.373 [Article][Crossref] [PubMed][Google Scholar] 